\title{
Acquisition of L2 English adverb placement by L1 Russian and Greek Cypriot speakers
}

Sviatlana Karpava

University of Central Lancashire, Cyprus

https://doi.org/10.36505/ExLing-2017/08/0013/000315

\begin{abstract}
This study investigates the acquisition of L2 English adverb placement by L1 Russian and L1 Greek Cypriot speakers. It aims to find out whether structural differences and similarities among English, Russian and Greek lead to facilitative or negative syntactic transfer effect in L2 acquisition of English. The results of the grammaticality judgment task showed that there is a facilitative transfer from L1 Russian into L2 English and negative transfer from L1 CG into L2 English. It was found that the participants had a better performance on the adverbs of frequency rather than on adverbs of manner. L2 proficiency and years of L2 learning affect adverb placement and the rate of cross-linguistic influence.
\end{abstract}

Key words: adverb placement, word order, L2 English, Russian, Cypriot Greek

\section{Introduction}

This study investigates the acquisition of L2 English adverb placement by L1 Russian and L1 Greek Cypriot (CG) speakers. It aims to find out whether structural differences and similarities among English, Russian and Greek lead to facilitative or negative syntactic transfer effect in L2 acquisition of English.

According to Alexiadou and Anagnostopoulou (1998), the difference between Greek and English can be explained by universally fixed adverb positions and verb movement. Greek is a null subject language, with V-movement. Verb-adverb word order is licensed in Greek, but not in English or Russian, while adverb-verb word order is allowed in Russian and English (Kallestinova and Slabakova, 2008; Mykhaylyk et al., 2015), but not in Greek or CG.

The unmarked position of frequency adverbs in Greek is postverbal (SVadvO), while pre-subject, sentence initial (AdvSVO) is marked, but not completely impossible. The grammatical position of manner adverbs is post-object (SVOadv), whereas pre-subject position (AdvSVO) is marked (Alexiadou and Stavrakaki, 2005).

In English, the unmarked position of frequency adverbs is preverbal (SadvVO), though post-object and pre-subject are allowed as well, while the grammatical position of adverbs of manner is post-object (SVOadv), though pre-verbal and pre-subject placement is also licensed. Post-verbal position,

ExLing 2017: Proceedings of 8th Tutorial and Research Workshop on Experimental Linguistics, 19-22 June, Heraklion, Crete, Greece 
both for adverbs of manner and frequency, in the sentences with direct object is ruled out.

The Generalized Inversion Hypothesis (Bailyn, 2004) suggests that in Russian SVO sentences adverbs of frequency and manner are allowed in preverbal position but not in post-verbal, though the latter is not considered fully ungrammatical and has degraded status (Kallestinova and Slabakova, 2008).

This study is an attempt to look into the complex process of L2 English acquisition of adverb placement by L1 Russian and CG speakers, whether there is cross-linguistic interference on syntax-semantics interface and whether adverb (mis)placement depends on the type of adverb, VP-internal and VP-external, age, length of exposure to L2 and level of L2 proficiency.

\section{Methodology}

The participants of the study were $100 \mathrm{CG}$ undergraduate students, 17-24 years old, 50 males and 50 females. The other group of the participants were 25 L1 Russian learners of L2 English, 17-28 years old, 19 females and 6 males. The L2 English proficiency of the participants was measured by IELTS test: listening, reading, writing and speaking.

The grammaticality judgement task was implemented, which had the following conditions: (i) pre-subject position of adverb, sentence initial position, allowed in English, Greek and Russian, for both manner and frequency adverbs; (ii) pre-verbal position of adverb, grammatical in English and Russian, for both manner and frequency adverbs, and ungrammatical in Greek; (iii) post-verbal position of adverb, ungrammatical in English and Russian, for both manner and frequency adverbs, but unmarked in Greek only for frequency adverbs; (iv) post-object position of adverb, sentence final position, allowed in English and Russian, for both manner and frequency adverbs, but licensed only for adverbs of manner in Greek.

The participants had to rate the grammaticality of the sentences, using Likert scale from 1 (totally incorrect) to 5 (totally correct). The task was focused on adverb placement, but there were also distractor items on the use of tenses and subject-auxilliary inversion. The participants were tested on the placement of adverbs of manner and frequency. The linguistic (socioeconomic) background questionnaires were used as well.

\section{Results and discussion}

The analysis of the data showed that for the first condition, pre-subject position of adverb, there is no difference between Russian and CG students. Sentence initial position of adverb is allowed in Russian and Greek. Both groups of the participants had higher rating (mean) for the sentences with 
adverbs of frequency than adverbs of manner. This could suggest that the type of the adverb might affect the grammaticality judgment of L2 English sentences.

Regarding the second condition, it was found that Russian students scored higher (mean rating scores of the grammaticality judgment task) in comparison to CG students. This could be explained by positive transfer from L1 Russian and negative transfer from L1 CG. Also, the rating for the adverbs of frequency were higher than for the adverbs of manner, for both groups of the participants.

There was not revealed any difference between Russian and CG students with respect to the third condition, post-verbal position of adverb. Both L1 Russian and L1 CG learners of L2 English scored lower for the adverbs of frequency than for the adverbs of manner.

Concerning the fourth condition, Russian students scored higher for the sentences with adverbs of manner and lower than CG students for the sentences with adverbs of frequency. The performance of the participants on this condition could be explained by positive transfer from L1 Russian and L1 CG. The details are provided in Table 1.

Table 1. Grammaticality judgment task, adverb placement, mean scores.

\begin{tabular}{|l|l|l|l|}
\hline \hline Adverb position & Adverbs & Russian students & CG students \\
\hline Pre-subject & Manner & 2.67 & 2.65 \\
\cline { 2 - 4 } & Frequency & 3.17 & 3.15 \\
\hline Pre-verbal & Manner & 3.95 & 3.27 \\
\cline { 2 - 4 } & Frequency & 4.41 & 3.68 \\
\hline Post-verbal & Manner & 3.35 & 3.28 \\
\cline { 2 - 4 } & Frequency & 3.03 & 3.01 \\
\hline Post-object & Manner & 4.07 & 3.67 \\
\cline { 2 - 4 } & Frequency & 3.18 & 3.37 \\
\hline \hline
\end{tabular}

According to one-way ANOVA, years of exposure to L2 English, years of learning L2 English, is a statistically significant factor for pre-verbal placement of frequency adverbs $(F(24)=34.778, p=.007)$ in the grammaticality judgment task by Russian students.

IELTS scores, level of L2 English proficiency, is a statistically significant factor for pre-subject placement of manner adverbs $(F(99)=3.666, p=.002)$ and pre-subject placement of frequency adverbs $(F(99)=3.141, p=.007)$ in the grammaticality judgment task by CG students.

According to paired samples t-test, there is a statistically significant difference between manner and frequency adverbs in pre-subject position $(t(99)=-5.663, p=.000)$; pre-verbal position $(t(99)=-2.730, p=.009)$; post - 
verbal position $(t(99)=2.577, p=.014)$ and post-object position $(t(99)=$ $2.708, p=.010)$ in the grammaticality judgment task by CG students; in presubject position $(t(24)=-2.592, p=.032)$; pre-verbal position $(t(24)=-3.496$, $p=.008)$ and post-object position $(t(24)=3.286, p=.011)$ in the grammaticality judgment task by Russian students.

The results showed that with respect to the grammaticality judgment task there is a facilitative transfer from L1 Russian into L2 English and negative transfer from L1 CG into L2 English. Overall, Russian students performed better than CG students.

It was found that L2 learners of English had a better performance with respect to the adverbs of frequency than the adverbs of manner, which could be the evidence that verb movement is sensitive to adverb hierarchy: frequency>manner (Cinque, 1999).

L2 proficiency, length of exposure to L2 English, years of L2 learning, affect adverb placement and the rate of cross-linguistic influence. L1 transfer is more evident at the early rather than at the advanced stages of L2 acquisition.

\section{References}

Alexiadou, A. and Anagnostopoulou, E. 1998. Parametrizing Agr: word order, verbmovement and EPP-checking. Natural Language and Linguistic Theory 16, 491539.

Alexiadou, A. and Stavroula Stavrakaki, S. 2005. Functional categories and clause structure in a Greek-English speaking bilingual patient with Broca's Aphasia: Evidence from adverb placement. In Cohen, J., McAlister, K., Kellie Rolstad, K. and MacSwan, J. (eds.), ISB4: Proceedings of the 4th International Symposium on Bilingualism, 39-57. Somerville, MA: Cascadilla Press.

Bailyn, J. 2004. Generalized inversion. Natural Language and Linguistic Theory 22, $1-49$.

Cinque, G. 1999. Adverbs and Functional Heads: A Cross-linguistic Perspective. New York: Oxford University Press.

Kallestinova, E. and Slabakova, R. 2008. Does the verb move in Russian? In Antonenko, A., Bailyn, J. and Bethin, C. (eds.), Proceedings of FASL 16, 199214. Michigan Slavic Publications.

Mykhaylyk, R., Mitrofanova, N., Rodina, Y. and Westergaard, M. 2015. The Linguistic Proximity Model: The case of Verb-Second revisited. In Grillo, E. and Jepson, K. (eds.), Proceedings of the 39th annual Boston University Conference on Language Development, 337-349, Sommerville, MA, Cascadilla Press. 